\title{
Pregnancy Discrimination in the European Union Law Its Legal Character and the Scope of Pregnant Women Protection*
}

\author{
Justyna Maliszewska-Nienartowicz
}

\author{
Associate Professor, The Faculty of Political Sciences and International Studies \\ Nicolaus Copernicus University, Ul. Stefana Batorego 39 L, 87-100 Toruń, Poland \\ e-mail: mal-nie@econ.umk.pl, phone no: +48 607843186
}

\section{Doi:10.5901/mjss.2013.v4n9p441}

\section{Abstract}

\begin{abstract}
Protection of women in relation to pregnancy and maternity is generally regulated in the Council Directive 92/85/EEC of 19 October 1992 on the introduction of measures to encourage improvements in the safety and health at work of pregnant workers and workers who have recently given birth or are breastfeeding. However, pregnancy discrimination has been the subject of numerous rulings issued by the Court of Justice of the European Union. On the basis of this case-law several questions can be asked. Most of them concern the legal character of pregnancy discrimination and the scope of pregnant women protection. Therefore, the first part of the article will focus on the problem of relations between pregnancy and sex discrimination. It will also consider if pregnancy discrimination should be based on comparison. The second part of the contribution will concentrate on the question if pregnancy discrimination is direct or indirect one or maybe we should refer to a special protection approach. Finally, the scope of pregnant women protection will be presented. The article will try to answer the question if further actions are necessary to tackle pregnancy discrimination, including the adoption of new regulations by the European Union or the change of the Court of Justice's position.
\end{abstract}

Keywords: pregnancy discrimination, protection of maternity, direct and indirect discrimination, objective justification, Council Directive 92/85/EEC

\section{Introducion}

Article 119 of the Treaty establishing European Economic Community concerning equal pay for equal work was the first regulation which referred to equality between women and men. It was introduced largely to serve an economic purpose France insisted on the inclusion of this provision fearing that the additional costs created by its worker protection legislation, including its law on equal pay would put it at a competitive disadvantage in the Common Market (Barnard, 1998: 352). This provision was followed by several directives adopted by the Council, in particular: Directive 75/117/EEC of 10 February 1975 on the approximation of the laws of the Member States relating to the application of the principle of equal pay for men and women (OJ L 45, 19.02.1975, p. 19-20); Directive 76/207/EEC of 9 February 1976 on the implementation of the principle of equal treatment for men and women as regards access to employment, vocational training and promotion, and working conditions ( OJ L 39, 14.02.1976, p. 40-42) and Directive 79/7/EEC of 19 December 1978 on the progressive implementation of the principle of equal treatment for men and women in matters of social security (OJ L 6, 10.01.1979, p. 24-25).

At the time of the adoption of these acts it was not thought necessary to treat pregnancy discrimination as a separate issue. Therefore, it was not regulated in details - article 2 (3) of Directive 76/207/EEC provided only that this act 'shall be without prejudice to provisions concerning the protection of women, particularly as regards pregnancy and maternity'. Thus, measures ensuring such protection were to be treated as an exception to the general prohibition of discrimination based on sex.

On the basis of this provision the Court of Justice developed many standards concerning pregnancy and maternity. At the same time it underlined that Directive 76/207/EEC 'is not designed to settle questions concerning the organisation of the family or to alter the division of responsibility between parents' (see case Hofmann $v$ Barmer Ersatzkasse, 184/83 [1984] ECR 3047). In this way it wanted to show that the private sphere was beyond the reach of EC law (Hervey \& Shaw, 1998: 50).

\footnotetext{
*Article prepared in the frames of the project financed by the National Centre of Science (decision no. DEC-2011/01/B/HS5/00965).
} 
It is, however, uncertain what approach should be adopted towards pregnancy discrimination - should it be treated as sex discrimination or not? The question also arises whether this kind of discrimination is direct or indirect. The answer to these questions is important as it influences the level of pregnant women protection. Therefore, the article starts with the problem of relations between pregnancy and sex discrimination. It also analyses whether it is important to find a comparator in order to state that pregnancy discrimination has occurred. Then the question of the form of discrimination is discussed. Finally, the scope of pregnant women protection is presented. The analysis takes into account the provisions of Directive 92/85/EEC of 19 October 1992 on the introduction of measures to encourage improvements in the safety and health at work of pregnant workers and workers who have recently given birth or are breastfeeding (OJ L 348 , 28.11.1992, p. 1-7) adopted by the Member States to strengthen the protection of this group of workers. Moreover, the Court of Justice has introduced many standards concerning pregnancy and maternity on the basis of the general provisions of both Directive 76/207/EEC and Directive 92/85/EEC. Therefore, it is important to present at least some of its rulings in this field.

\section{Pregnancy discrimination as non-comparative and sex discrimination}

In the famous case Dekker (C-177/88 [1990] ECR I-3941) the Court of Justice was asked whether the refusal to employ a woman who was a suitable candidate because of the adverse consequences owing to the fact that she was pregnant amounted to direct or indirect sex discrimination. It underlined that the answer to this question 'depends on whether the fundamental reason for the refusal of employment is one which applies without distinction to workers of either sex or, conversely, whether it applies exclusively to one sex'. The Court of Justice had no doubts that this reason was connected with pregnancy and that only women can be refused employment on this ground. Consequently, it held that such a refusal constituted direct discrimination on grounds of sex. It also underlined that this conclusion could not be influenced by the absence of male candidates.

In this way the Court of Justice seems to indicate that a finding of this kind of sex discrimination does not require a comparison to be made between the treatment of women and either a real or hypothetical man (Honeybell, 2000: 47). Should we then treat pregnancy discrimination not only as sex discrimination but also as non-comparative discrimination? Is the approach presented by the Court of Justice a correct one? It explains it in the case Webb (C-32/93 [1994] ECR I-3567), stating that 'pregnancy is not in any way comparable with a pathological condition, and even less so with unavailability for work on non-medical grounds'.

Generally, such an approach is seen as appropriate in academic writing (see Tobler, 2005: 48, with further references). Most authors underline that doing away with the requirement of a male comparator makes it easier to establish pregnancy discrimination. It is also indicated that pregnancy and parenting do not fit neatly into the equality model, based as it understandably is upon the need of comparator (James, 2011: 55). There are, however, authors who challenge the Court's approach and argue that it is necessary to make comparison even in cases of pregnancy discrimination. For instance, Wintemute (1998: 25) states that 'comparison is an essential feature of any claim of direct or indirect discrimination (...) claims of discrimination without comparison are impossible'. Honeybell (2000: 52) comes even to such a conclusion that 'the concept of discrimination is meaningless without an element of comparison'.

On the one hand, the approach which treats pregnancy as a state not comparable to any pathological condition should be welcomed. On the other, however, the Court of Justice refers it only to pregnancy and illness which occurs during that period and maternity leave. If the illness arises after the end of maternity leave, then it is permissible to apply a comparison with a sick man. This was underlined in the case Hertz (C-179/88 [1990] ECR I-3979) decided on the same day as Dekker where the Court found that 'in the case of an illness manifesting itself after the maternity leave, there is no reason to distinguish an illness attributable to pregnancy or confinement from any other illness (...) Male and female workers are equally exposed to illness'. The sick-male approach has not been eliminated in subsequent case-law. For instance, in the case Brown (C-394/96 [1998] ECR I-4185) the Court came to conclusion that:

dismissal of a female worker during pregnancy for absences due to incapacity for work resulting from her pregnancy is linked to the occurrence of risks inherent in pregnancy and must therefore be regarded as essentially based on the fact of pregnancy. Such a dismissal can affect only women and therefore constitutes direct discrimination on grounds of sex. However, where pathological conditions caused by pregnancy or childbirth arise after the end of maternity leave, they are covered by the general rules applicable in the event of illness.

Thus, the Court of Justice has provided only the minimum of protection necessary to ensure that women are not dismissed while still pregnant (Wynn, 1999: 447). Moreover, its approach towards illness occurring after the end of 
maternity leave is connected with comparison, usually with a sick man. The Court does not explain why it treats pregnancy as a special state, not comparable with a pathological condition and illness occurring after the end of maternity leave even if it is attributable to pregnancy as a normal situation which can be compared to other illnesses. It seems that it has tried to take into account the cost arguments presented by Advocate General Colomer it its opinion given in the case Brown. He underlined that the prohibition of dismissal 'would be liable to entail not only administrative difficulties and unfair consequences for employers but also repercussions on the employment of women'. This, however, appears to justify post-entry discrimination by reference to the risk of pre-entry discrimination and does not take into account the cost to pregnant women who may risk unemployment if they do not return to work after maternity leave (Wynn, 1999: 441).

Whatever reasons lie behind this approach, it should be noticed that it is not entirely consistent. Therefore, some authors refer to the so-called 'but-for' test formulated by the British House of Lords in case James (1990, 2 AC 751). The correct formulation of this test in pregnancy case is to determine whether the different treatment would have occurred but for the pregnancy. Such test does not refer to a comparator but it does not abandon the requirement of comparison (Honeybell, 2000: 49). There is no doubt that in order to answer the question if a woman would have been treated differently but for the fact that she was pregnant it is necessary to compare her situation with a non-pregnant person.

It should noticed that the group of non-pregnant persons include not only men but also those women who are not pregnant either because they do not want or they cannot have children. Thus, the question arises if pregnancy discrimination should be seen as sex discrimination? The Court of Justice explains its position in the following way discrimination on the grounds of pregnancy can only happen to a woman, so it is connected with sex and as such amounts to sex discrimination. However, this approach does not take into account other possible roots of pregnancy discrimination - it may be, for example, nothing to do with gender at all, but caused by a desire to hurt the young, the heterosexual or the non-celibate, or caused by the jealousy of those (men or women) who are able to have children (Honeybell, 2000: 51). Moreover, the result of the Court decisions which locate pregnancy discrimination as a gender issue is such that all negative pregnancy and parenting workplace relationships are seen as ones that only impact upon women (see James, 2011: 55). Therefore, it would be better to treat pregnancy as a special ground although connected with sex. Such an approach would be consistent with the above-mentioned 'but-for' test.

The problem is that the EU anti-discrimination law concentrates on equality of men and women and although a separate act concerning pregnancy was adopted (Directive 92/85/EEC), any less favourable treatment of a woman related to pregnancy or maternity leave within the meaning of this Directive is treated as sex discrimination. This is underlined in article 2 (2) (c) of Directive 2006/54/EC of the European Parliament and of the Council of 5 July 2006 on the implementation of the principle of equal opportunities and equal treatment of men and women in matters of employment and occupation (OJ L 204, 26.07.2006, p. 23-36). Such a regulation is undoubtedly influenced by the caselaw of the Court - the recital 23 of the preamble to Directive 2006/54 directly refers to it. Consequently, it would be good if the Court of Justice reconsider its approach towards pregnancy discrimination. Then national courts and other organs applying the law could get better directions how to protect pregnant women in workplace relationships.

\section{Pregnancy discrimination - direct, indirect sex discrimination or a special protection approach?}

According to the definitions included in the secondary law of the European Union (e.g. Directive 2006/54) direct discrimination occurs where one person is treated less favourably than another is, has been or would be treated in a comparable situation, on the basis of any of the prohibited grounds such as sex, racial or ethnic origin, religion, disability, age or sexual orientation. In contrast, indirect discrimination takes place where an apparently neutral provision, criterion or practice would put persons protected by the general prohibition of discrimination at a particular disadvantage compared with other persons unless that provision, criterion or practice is objectively justified by a legitimate aim and the means of achieving that aim are appropriate and necessary.

The distinction between direct and indirect discrimination is important not only from theoretical but also a practical point of view. From the perspective of the victim of the alleged discrimination, a finding of its direct form will always be preferable because of the usually more limited justification possibilities and because of the difficulties involved in proving disparate impact which is required in the case of indirect discrimination (Tobler 2005: 307).

Pregnancy discrimination is generally considered by the Court of Justice as direct sex discrimination. In the abovementioned case Dekker it found that 'only women can be refused employment on grounds of pregnancy and such a refusal therefore constitutes direct discrimination on grounds of sex'. It also underlined that:

the reply to the question whether the refusal to employ a woman constitutes direct or indirect discrimination depends on 
the reason for that refusal. If that reason is to be found in the fact that the person concerned is pregnant, then the decision is directly linked to the sex of the candidate.

In this way the Court underlined that if a differential treatment is based on a criterion inextricably linked to the ground prohibited in the legal provisions, it leads to direct discrimination. This approach was generally welcomed by Advocates General and commentators. For instance, Advocate General Jacobs in his opinion given in the case Schnorbus (C-79/99 [2000] ECR I-10997) indicated that 'discrimination is direct where the difference in treatment is based on a criterion which is either explicitly that of sex or necessarily linked to a characteristic indissociable from sex'. Similarly, Advocate General Kokott in her opinion in case Ingeniørforeningen i Danmark (C-499/08 [2010] ECR I-9343) found that:

\begin{abstract}
direct discrimination may also occur where a difference in treatment is based on a criterion which appears to be neutral at first sight but is in reality inextricably linked to the ground for differentiation prohibited by the European Union legislature. For example, the Court has held that direct (and not merely indirect) discrimination on grounds of sex occurs where an employer's action is linked to the existence or non-existence of pregnancy, as pregnancy is directly linked to the sex of an employee.
\end{abstract}

In the academic writing it is underlined that treating pregnancy discrimination as a direct form is advantageous for pregnant women - direct discrimination cannot be justified in such a broad way as indirect one. It is even found that in this way the Court takes into account the remedial function of the anti-discrimination law (e.g. Ellis 1994: 568). However, some authors notice that treating pregnancy discrimination as direct sex discrimination in all cases makes some of the Court's decisions difficult to explain (Wintemute 1998: 29).

Indeed, the Court in the case Hertz found that:

although certain disorders are, it is true, specific to one or other sex, the only question is whether a woman is dismissed on account of absence due to illness in the same circumstances as a man; if that is the case, then there is no direct discrimination on grounds of sex (\$16 and 17).

This shows that the Court is not willing to treat all disadvantageous treatment related to pregnancy and maternity as direct sex discrimination. Only during pregnancy and the statutory pregnancy or maternity leave it is granted legal recognition as discrimination on grounds of pregnancy and thereby directly on sex. Thereafter, it is considered to be based on illness and as such could amount to no more than indirect sex discrimination if it can be shown that considerably more women than men suffer from such long-term 'illness' (Tobler 2005: 347 and 348).

Consequently, some commentators suggest to treat discrimination on grounds of pregnancy and maternity as indirect sex discrimination (see Wintemute 1998: 30-36). However, such a position is not generally seen as correct in academic writing in particular because of the possibility of broader justification than is the context of direct sex discrimination. Furthermore, it is noticed that indirect discrimination is to some extent dependent upon chance fact - it may be that a requirement or condition is applied to pregnant women which they would much more easily satisfy if they were not pregnant, but no indirect discrimination claim will lie unless this happens to be more easily satisfied by a higher proportion of men (Honeybell, 2000: 47). It seems that this was one of the main reason why the Court of Justice decided to treat pregnancy discrimination as direct sex discrimination. Therefore, it will not be willing to change its position in this regard.

However, the Court could consider whether unfair treatment on grounds of pregnancy should be seen only in terms of discrimination whether direct or indirect or maybe it would be better to apply a special protection approach. It allows to take into account employers' positive obligations to accommodate pregnant women when they have different needs (see Wintemute, 1998: 35). Undoubtedly, such an approach serves pregnant women interests in a better way than a simple negative obligation to refrain from treating them less favourably than other (usually male) workers. Therefore, in the academic writing it was underlined that it is necessary to adopt a separate corpus of rules governing pregnancy outside traditional sex discrimination law (see Tobler, 2005: 349 with further references).

To certain extent this problem was solved by the adoption of Directive 92/85/EEC. However, this act does not regulate all issues connected with pregnancy and maternity. Beyond the limited reach of the Directive, the equality approach with all its inherent difficulties remains relevant, including the problem of distinguishing when to find direct as opposed to indirect sex discrimination. That, of course, is not a satisfactory state of affairs (Tobler, 2005: 350) Moreover, the Court of Justice still applies the discrimination approach even if it refers to the provisions of Directive 92/85/EEC which are not framed in terms of discrimination. For instance, in the case Tele Danmark (C-109/00 [2001] ECR I-6993) it 
underlined that the dismissal of a worker on account of pregnancy constitutes direct discrimination on grounds of sex and it does not matter if the contract of employment was concluded for a fixed or an indefinite period. The Court added that 'Directives 76/207 and 92/85 do not make any distinction, as regards the scope of the principle of equal treatment for men and women, according to the duration of the employment relationship in question'. Thus, it refers to the principle of equal treatment for men and women in the context of Directive 92/85/ECC although it is based on a special protection approach. It seems that the Court should reconsider its position in this regard and refer to special protection approach.

\section{The Scope of Pregnant Women Protection - provisions of Directive 92/85/EEC and the case-law of the Court}

In order to see if the pregnant women protection in the EU law is sufficient, one should also look at its scope. This can be determined on the basis of both the provisions of Directive 92/85/EEC and the relevant case-law of the Court of Justice that despite the above-mentioned limited approach has introduced many standards concerning protection of pregnancy and maternity.

According to article 1 of Directive 92/85/ECC its purpose is 'to implement measures to encourage improvements in the safety and health at work of pregnant workers and workers who have recently given birth or who are breastfeeding'. It should be noticed that this act does not refer to the principle of equal treatment for men and women - instead it underlines the special role of the latter in relation to pregnancy and maternity. Therefore, it obliges both the Member States and employers to undertake all the necessary measures to protect pregnant woman.

Firstly, if the results of the assessment of the working conditions reveal a risk to the safety or health or an effect on the pregnancy or breastfeeding of a worker, the employer 'should take the necessary measures to ensure that, by temporarily adjusting the working conditions and/or the working hours of the worker concerned, the exposure of that worker to such risks is avoided' (article 5 (1) of Directive 92/85/EEC). If the adjustment of her working conditions and/or working hours is not technically and/or objectively feasible, or cannot reasonably be required on duly substantiated grounds, the employer should take the necessary measures to move the worker concerned to another job and if this is not possible, then the worker concerned should be granted leave in accordance with national legislation and/or national practice for the whole of the period necessary to protect her safety or health (article 5 (2) and (3) of Directive 92/85/EEC).

Secondly, the Member States should take the necessary measures to ensure that pregnant workers and workers who have recently given birth or who are breastfeeding are not obliged to perform night work during their pregnancy and for a period following childbirth which should be determined by the national authority competent for safety and health.

Thirdly, the Member States should ensure that pregnant workers and workers who have recently given birth or who are breastfeeding are entitled to a continuous period of maternity leave of a least 14 weeks allocated before and/or after confinement in accordance with national legislation and/or practice.

Fourthly, pregnant workers should be entitled to, in accordance with national legislation and/or practice, time off, without loss of pay, in order to attend ante-natal examinations, if such examinations have to take place during working hours.

Fifthly, the Members States should take the necessary measures to prohibit the dismissal of pregnant workers and workers who have recently given birth or who are breastfeeding during the period from the beginning of their pregnancy to the end of the maternity leave, save in exceptional cases not connected with their condition which are permitted under national legislation and/or practice (article 10 (1) of Directive 92/85/EEC). This means that if there are serious reasons for dismissing a pregnant woman, in particular connected with her behaviour e.g. neglecting work duties, then it not excluded. However, the employer must give important reasons for dismissal.

Finally, Directive 92/85/EEC refers to the employment rights, in particular the maintenance of a payment and/or entitlement to an adequate allowance in cases of moving pregnant workers and workers who have recently given birth or who are breastfeeding to another job or in cases of granting them leave. Similar rights should be granted for workers on maternity leave. It is also underlined that the allowance for such workers should 'be deemed adequate if it guarantees income at least equivalent to that which the worker concerned would receive in the event of a break in her activities on grounds connected with her state of health, subject to any ceiling laid down under national legislation' (article 11 (3) of Directive 92/85/EEC). This provision has been the subject of several judgments of the Court of Justice.

Generally, its case-law concentrates on the following issues: the protection against refusal to employ or dismissal on grounds of pregnancy, entitlement to pay or adequate benefit for pregnant workers and those on maternity leave, the protection against unfair treatment and ensuring promotion during pregnancy and maternity leave (see further Maliszewska-Nienartowicz, 2013). In relation to the first question the Court of Justice underlines that dismissal of a female worker on grounds of pregnancy constitutes direct sex discrimination. It founds that 'dismissal of a pregnant 
woman recruited for an indefinite period cannot be justified on grounds relating to her inability to fulfil a fundamental condition of her employment contract' (see the above-cited case Webb). According to the case-law the protection of pregnant women against dismissal applies to both employment contracts for an indefinite period and fixed-term contracts. Although non-renewal of such a contract, when it comes to an end as stipulated, is not treated as a dismissal prohibited by article 10 of Directive 92/85/EEC the Court indicates that when it is motivated by the worker's state of pregnancy, it constitutes direct discrimination on grounds of sex (case Melgar C-438/99 [2001] ECR I-6915).

However, the Court draws a clear distinction between pregnancy and illness, even where the illness is attributable to pregnancy but manifests itself after the maternity leave - it points out that, there is no reason for distinguishing such an illness from any other illness (see e.g. the above-cited cases Hertz and Brown). Consequently, it presents the view that pathological conditions caused by pregnancy or childbirth which arise after the end of maternity leave are covered by the general rules applicable in the event of illness and a woman is not protected against dismissal on grounds of periods of absence. Such an approach highlights the limitations of the equality concept in dealing with female difference in the workplace, as positive discrimination in favour of motherhood is circumscribed by artificial time limits (see Wynn, 1999: 435). Thus, the EU law does not protect female workers against dismissal after the end of maternity leave. This is the result of both article 10 of Directive 92/85/EEC and the case-law of the Court of Justice which has not decided to interpret this provision in a broader way. As a result, the protection of women against dismissal after the end of maternity leave is left to the Member States and depends on national regulations.

Similar solution has been adopted in relation to the amount of pay or benefit for pregnant workers and those on maternity leave - their upper limits are determined by the Member States. In the case Gillespie (C-342/93 [1996] ECR I475) the Court of Justice indicated that:

\begin{abstract}
the principle of equal pay laid down in Article 119 of the Treaty and set out in detail in Directive 75/117 on the approximation of the laws of the Member States relating to the application of the principle of equal pay for men and women neither requires that women should continue to receive full pay during maternity leave, nor lays down specific criteria for determining the amount of benefit payable to them during that period, provided that the amount is not set so low as to jeopardize the purpose of maternity leave, which is the protection of women before and after giving birth. In order to assess the adequacy of that amount, the national court must take account, not only of the length of maternity leave, but also of the other forms of social protection afforded by national law in the case of justified absence from work.
\end{abstract}

It should be noticed that according to article 11 (3) of Directive 92/85/EEC benefit is deemed adequate 'if it guarantees income at least equivalent to that which the worker concerned would receive in the event of a break in her activities on grounds connected with her state of health, subject to any ceiling laid down under national legislation' Thus, the EU law does not require full pay or equivalent benefit during the maternity leave.

Unfortunately, the Court takes similar approach in relation to pay during the period of pregnancy. In the case McKenna (C-191/03 [2005] ECR I-7631) it underlined that:

\begin{abstract}
as it stands at present, Community law does not require the maintenance of full pay for a female worker who is absent during her pregnancy by reason of an illness related to that pregnancy. During an absence resulting from such an illness, a female worker may thus suffer a reduction in her pay, provided that she is treated in the same way as a male worker who is absent on grounds of illness, and provided that the amount of payment made is not so low as to undermine the objective of protecting pregnant workers.
\end{abstract}

Similarly, a worker temporarily transferred to another job during her pregnancy because of a risk to her safety or health is not entitled to the average pay received before such transfer if the payment of some of the supplementary allowances to which she was entitled was dependent on the performance of specific functions (case Parviainen, C471/08 [2010] ECR I-6533). However the Court underlined that:

\begin{abstract}
Article 11(1) of Directive 92/85 provides only for minimum protection with respect to the pay of pregnant workers covered by Article 5 thereof. None of the provisions of that directive prevents the Member States or, where appropriate, management and labour from providing for the maintenance of all the pay components and supplementary allowances to which the pregnant worker was entitled before her pregnancy and her temporary transfer to another job.
\end{abstract}

This means that both the Member States and the social partners may provide for the maintenance of their current pay, including all allowances to which they were entitled prior to pregnancy.

As far as the protection against unfair treatment and ensuring promotion during pregnancy and maternity leave is 
concerned, it should be noticed that the Court of Justice has introduced many standards which are headed to eliminate all disadvantages in employment that may arise due to pregnancy and maternity. In its case-law it underlines inter alia that a female worker:

- must be able to take her annual leave during a period other than the period of her maternity leave (Merino Gómez, C-342/01 [2004] ECR I-2605);

- should acquire rights to an insurance annuity which is part of a supplementary occupational pension scheme also during statutory maternity (Mayer, C-356/03 [2005] ECR I-295) or that

- should obtain at her request an alteration of the period of her child-care leave at the time when she claims her rights to maternity leave (Kiiski, C-116/06 [2007] ECR I-7643).

In the case Sass (C-284/02 [2004] ECR I-11143) the Court of Justice generally noticed that 'a female worker is protected in her employment relationship against any unfavourable treatment on the ground that she is or has been on maternity leave'. It also tries to ensure the women right to promotion. For instance, in the case Thibault (C-136/95 [1998] ECR I-2011) it stated that provisions of Directive 76/207/EEC 'preclude national rules which deprive a woman of the right to an assessment of her performance and, consequently, to the possibility of qualifying for promotion because she was absent from the undertaking on account of maternity leave'.

Thus, the Court of Justice aims to ensure not only the continuity of pregnant workers employment but also the protection of their rights. Its case-law has led to the repeal of many disadvantageous regulations contained in legislation as well as in collective agreements. Similarly, the Court aims to provide pregnant workers and those on maternity leave with opportunities to improve their employment situation, including the promotion (Maliszewska-Nienartowicz, 2013: 36).

\section{Conclusions}

On the whole it should be noticed that the Court of Justice has been active in fighting against pregnancy discrimination in the workplace. However, its approach towards this issue does not appear to be correct in all cases. First of all, the Court has constantly referred to pregnancy discrimination as direct sex discrimination. Such an approach could be influenced by the lack of any special EU regulations in this field but since the adoption of Directive 92/85/EEC the Court of Justice has had the possibility to change its position and treat pregnancy as a state which requires special protection. Referring to pregnancy only in terms of discrimination does not allow to take into account pregnant women needs in a complex way. Therefore, it would be good if the Court reconsidered its approach.

Moreover, both the provisions of Directive 92/85/EEC and the case-law of the Court apply to the benefit of women only in certain context. The most important restriction is connected with the fact that women are not protected against dismissal after the end of maternity leave. It seems that the Court's approach towards this issue is influenced by national autonomy in matters of social affairs. Therefore, only the Member States could change the regulation contained in article 10 of Directive 92/85/EEC and extend the period of protection against dismissal based on the absence at work because of an illness attributable to pregnancy. Similar remarks can be made in relation to provisions concerning maintenance of a payment or entitlement to an adequate allowance during pregnancy and maternity leave. However, Directive 92/85/EEC does not directly refer to the issue of pay for a female worker who is absent during her pregnancy by reason of an illness related to that pregnancy. It seems, therefore, that the Court of Justice could develop higher protection standards in this field even though the EU law does not require the maintenance of full pay. Anyway in my opinion pregnant women and those on maternity leave should receive full pay or an equivalent allowance. It is not sufficient to guarantee income which they would receive in the event of absence at work because of an illness not related to pregnancy. This confirms that only a special protection approach is a proper solution to deal with the pregnant women situation.

\section{References}

Barnard C. (1998), The Principle of Equality in the Community Context: P, Grant, Kalanke and Marschall: Four Uneasy Bedfellows, Cambridge Law Journal, 57 (2), 352-373.

Ellis E. (1994), The Definition of Discrimination in European Community Sex Equality Law, European Law Review, 19 (6), 563-580.

Hervey T., Shaw J. (1998), Women, Work and Care in EC Law, Journal of European Social Policy, 8 (1), 43-63.

Honeyball S. (2000), Pregnancy and Sex Discrimination, Industrial Law Journal, 29 (1), 43-52.

James G. (2011), The Law Relating to Pregnancy and Maternity Leave. In T. Wright \& H. Conley (eds), Gower Handbook of Discrimination at Work (pp. 47-56). Farnham, Gower Publishing Ltd.

Maliszewska-Nienartowicz J. (2012), Dyskryminacja pośrednia w prawie Unii Europejskiej, Toruń, Wydawnictwo Naukowe UMK. 
Maliszewska-Nienartowicz J. (2013), Ochrona kobiet w związu z ciążą i macierzyństwem w świetle wybranych rozstrzygnięć Trybunału Sprawiedliwości UE, Europejski Przegląd Sądowy, 3, 31-39.

Tobler Ch.(2005), Indirect Discrimination: A Case Study into the Development of the Legal Concept of Indirect Discrimination under EC Law, Antwerpia - Oxford, Intersentia.

Wintemute R. (1998), When is Pregnancy Discrimination Indirect Sex Discrimination?, Industrial Law Journal, 27 (1), 23-36.

Wynn M. (1999), Pregnancy Discrimination: Equality, Protection or Reconciliation?, The Modern Law Review, 62 (3), 435-447. 